\title{
Mode and tempo in Western classical music of the common- practice era: My grandmother was largely right - but no one knows why
}

\author{
VLADIMIR J. KONEČN ${ }^{[1]}$ \\ Department of Psychology, University of California, San Diego
}

\begin{abstract}
The work of Post and Huron (2009) is an example of how the received wisdom in musicology can be fruitfully challenged by simple empirical procedures - in this case demonstrating a counterintuitive, yet strong, relationship between the minor mode and fast tempi in the Romantic era. The fact that the authors' explanation in terms of the emotional similarities of the minor mode with the Sturm und Drang attributes (other than "sadness") is not wholly convincing in music-historical terms does not diminish the importance of the finding. However, there is still no resolution of the central psychological conundrum of why the minor mode is generally associated with "sadness." And it is unclear why the authors drew on speech prosody rather than human emotion-driven and emotion-expressing movement for their tempo observations. There are other aspects of the data that require further exploration. One is the differential distribution of the associations of various tempo markings with mode across the periods of the common-practice era. Another is the $3: 1$ preponderance of allegro over adagio in the authors' search of 50,000 tracks in the ClassicsOnline.com database and the possibility that this ratio is a partial consequence of the psychological implications of the sonata form that were intuitively understood and used by composers.
\end{abstract}

Submitted 2009 February 6; accepted 2009 February 10.

KEYWORDS: expressiveness of music, minor mode, major mode, tempo, allegro, adagio, sonata form

THE two studies by Post and Huron (2009) are a fine example of how the assumptions and the received wisdom in musicology can be fruitfully challenged even by quite simple empirical procedures (cf. Batt, 1987; Gotlieb \& Konečni, 1985; Karno \& Konečni, 1992; Konečni, 1987). On a personal note, I distinctly remember "receiving the wisdom" from my maternal grandmother who taught me, when I was about six years of age, that compositions in the minor mode tended to sound sad and were usually in a slow tempo and, conversely, that the quick allegro and the slow adagio movements were predominantly in the major and minor modes, respectively. Since my grandmother was clearly speaking of music from the entire common-practice era, very much including the Romantic period, several aspects of the Post-Huron results come as a considerable surprise to me (and I dare say they will to many others).

The overall lack of a significant association between mode and tempo that is evident in their Table 1 must have come as a shock to Post and Huron, for one would think that their original intent in doing the study was simply to document the received wisdom quantitatively and to determine the exact strength of the expected association. Fortunately, the authors' sampling was sufficiently broad and deep to allow them to carry out meaningful tests within the Baroque, Classical, and Romantic periods individually (on the basis of the data in Table 2). Since these were post hoc statistical analyses, it could be argued that all three of these tests should have been two-tailed, instead of two of them being onetailed; but this is relatively unimportant in view of the fact that the one-tailed tests, when changed to two-tailed ones, would still be significant at the $p<.05$ level. One of the clear and surprising findings of Study 1, then, is that whereas the received wisdom that music in the minor mode is slower than that in the major was shown to be correct for the Baroque and Classical periods, there was a complete, statistically significant, reversal for the Romantic period. The "cute" title of the article by Post and Huron captures this factually correctly (but stylistically poorly, for it leads the reader to expect that more than three periods were studied: One out of only three is psychologically too high a proportion to justify the formulation in the title). 
The authors' decision to confine Study 2 to the theme-and-variations genre is defensible (in fact, inspired) - and here Post and Huron obtained what they consider to be strong support for the initially predicted association between mode and tempo. A perusal of their Table 3, however, reveals that in the case of only two of the seven studied theme-and-variations compositions (Schumann and Glazunov) the target variation is in the major mode (and therefore compared in tempo, given the procedure that was used, to the preceding and ensuing variations in the minor mode) - and these two are precisely the cases in which the received-wisdom hypothesis is partly or completely disproved. One would hope for more work to correct the current sampling asymmetry and examine its potential interpretive implications, as well as to look closely at the issue of (in)dependence of the two data points obtained within each work (an issue the authors raise themselves).

There are other interesting aspects of the data that are unfortunately treated only in passing or not at all by Post and Huron. One such issue is the individual association of the four tempo terms that were used in Study 1 (largo and adagio for slow tempi, allegro and presto for fast ones) with mode. "Eyeballing" Table 3, one sees a unique and markedly different pattern of association with mode for each of the four tempo terms across the Baroque, Classical, and Romantic periods. Largo is relatively evenly distributed between the major and minor modes in all three periods. Adagio is in the minor mode $63 \%$ of the time in the Baroque period, but in the major mode $70 \%$ or more of the time in both the Classical and Romantic periods (a double surprise). For the fast tempi, whereas presto is evenly distributed in Baroque, allegro is $77 \%$ of the time in the major mode during this period; but both allegro and presto are predominantly (over $80 \%$ ) in the major mode in the Classical period and both are predominantly $(60 \%$ and $73 \%$, respectively) in the minor mode in the Romantic period. These differential patterns for the tempo terms within and across the two tempo groups should be kept in mind when contemplating the implications of the main point that Post and Huron wish to drive home on the basis of Study 1; at the same time, these empirical findings may prove a useful corrective in the musicological work on tempo markings.

In fact, even the most basic and general results of the authors' search for the four tempo terms on ClassicsOnline.com hold both musicological and psychological interest: Post and Huron found 862 music tracks for largo, 2,163 for adagio, 6,879 for allegro, and 1,369 for presto. Can one make some sense, however tenuously and speculatively, of the fact that this rough search found 8,248 fast tracks compared to only 3,025 slow tracks, and, when comparing only the two most common terms for tempo from each group, that allegro exceeded adagio by a ratio of over 3 to 1 ? Part of the answer undoubtedly lies in the composers' desire to provide upbeat, "happy", material to the listening public; this desire is matched by the listeners' pro-"happy" "bias" when evaluating their own state upon listening to a carefully balanced diet of "happy" and "sad" tracks (Konečni, Brown, \& Wanic, 2008). Another, though I would claim related, part of the answer lies in the popularity of the four-movement sonataform compositions during the common-practice era; in them, the fast-slow-scherzo-fast conventional sequence of movements essentially guarantees a 2 to 1 numerical advantage to allegro over adagio. But this should not be considered an "artifact" by means of which one can dismiss the fast-tempo preponderance. Instead, one should ask if there are psychological reasons for this tempo-related convention in the four-movement sonata-form compositions and if they are partly responsible for the popularity of such compositions. ${ }^{1}$ Even if the semantic connection of adagio (Italian "ad agio" = at ease) to "sadness" is admittedly rather indirect (via "play it slow," etc.), the link of allegro to "happiness" (as the authors point out) is unambiguous, for the term means not just "quick" and "lively," but also "cheerful," "gay," and "merry."

Reasonable explanations can therefore be offered to account for the composers' frequent use of the fast-slow-scherzo-fast scheme, and specifically of allegro movements, with the latter based on the seemingly defensible assumption that allegro has been used simultaneously as a tempo marking and as the emotion that the movement in question ought to express or portray - which in itself suggests that there is a folk musical idea (with the composers and performers, as well as listeners, included in "folk") about the connection between the speed of a person's (and music's) movement and that person's felt emotional state (in the case of music, since it is not a sentient being, its "expression" or portrayal of emotion). As noted above, most composers in the common-practice era may have specifically wanted more happiness than sadness expressed in their music and the sonata form provided a convenient vehicle to achieve this. (Composers may have idealistically hoped for more happiness, or at least mirth, in the world, or thought that their allegro movements put listeners in a better mood and thus pleased them, or both.) But in a psychologically more complex and accurate manner, composers must have intuitively realized the importance of change and modulation in the "arousingness" (including through tempi) of their compositions (cf. Berlyne, 1971; Konečni, 1986) and of the desirable end result - an upbeat (mental-emotional or literal) departure by the listeners. The fast-slow-scherzo-fast sequence of the tempi can therefore perhaps be best understood as the composers' sequential "instructions" to 
listeners: be alert and listen! - contemplate deeper matters a little - chuckle a little - leave, feeling "up" and "merry"!

In the preceding discussion, allusions were repeatedly made to allegro and to some extent adagio as being related both to musical tempi and the different speeds of gait and body movements visible in people expressing their genuinely felt emotional states, or merely mimicking and communicating such states (including acting on the opera stage). In other words, the assumption has been, for example, that sad people move slowly (and also less frequently, but the density of events in both music and behavior is a separate, though related, matter), have bent shoulders, bodies closer to the ground, and so on. There is indeed a vast literature on the "iconic" aspects of music with regard to human emotion-driven movement that goes back at least to Avison (1752/2003). I find it therefore a little odd that Post and Huron ignored this very considerable literature that even spans various art forms and stated that their studies were instead motivated by parallels between emotional cues in music and speech prosody (legitimate and defensible as that is). One cannot help but wonder, first of all, if they hopefully unnecessarily - felt that frankly atheoretical, empirical studies would be considered less worthy even in a journal like Empirical Musicology Review, and, second, chose speech over physical movement because of the convenience of some references.

The authors of this very useful article cannot be blamed for the fact that several important questions - some new, some old - remain unanswered. The new one is the minor mode's strong association with fast tempi in the Romantic period (and the somewhat less strong association of the major mode with slow tempi, especially adagio, in the same period). The authors' ad hoc explanation of this result - in terms of the imputed similarity of the various alleged emotional connotations of the minor mode (in addition to sadness) with the Sturm und Drang attributes in art (discussed by Johann Georg Hamann, Johann Gottfried von Herder, von Goethe, and others, in the period 1767-1786) - is not wholly convincing, even in art-historical terms, partly because the Sturm und Drang movement temporally preceded German Romanticism (including in music, in which von Weber was perhaps its first pure proponent) by several decades, with the period of Weimar Classicism of von Goethe and von Schiller interpolated.

Moreover, one is now certainly not even a step closer to the resolution of the old, and central, conundrum: Why is the minor mode associated with sadness? Given the received musicological and music-psychological wisdom, Post and Huron feel rightly justified in formulating a "hypothesis [that] assumes an enculturated link between the minor mode and sadness" (italics added); they also say: "Instead of asking listeners to judge the sadness of passages, we simply assumed that music in the minor mode would tend to evoke or portray sadness for Western-enculturated listeners" (italics added). It seems that a key task for music historiography would be to search for the origins, development, and establishment of this convention ("enculturated link") and to this end the archives pertaining to the common-practice era composers' verbally expressed views on the relationship between mode and emotion, and particularly the minor mode and sadness, should be combed. On the other hand, music psychology's task would be to study in listeners the possible neuro-psychological reasons for what at present appears to be only a convention.

\section{NOTE}

[1] Correspondence should be addressed to Vladimir J. Konečni, Department of Psychology, University of California, San Diego, La Jolla, CA 92093-0109, USA. Email: vkonecni@ucsd.edu.

\section{REFERENCES}

Avison, C. (1752/2003). An essay on musical expression. Bristol, UK: Thoemmes Press.

Batt, R. (1987). Comments on "The effects of instrumentation, playing style, and structure in the Goldberg Variations by Johann Sebastian Bach.” Music Perception, 5, 207-213.

Berlyne, D. E. (1971). Aesthetics and psychobiology. New York: Appleton-Century-Crofts. 
Gotlieb, H., \& Konečni, V. J. (1985). The effects of instrumentation, playing style, and structure in the Goldberg Variations by Johann Sebastian Bach. Music Perception, 3, 87-102.

Karno, M., \& Konečni, V. J. (1992). The effects of structural interventions in the First Movement of Mozart's Symphony in G-Minor K. 550 on aesthetic preference. Music Perception, 10, 63-72.

Konečni, V. J. (1986). Bach's St Matthew Passion: A rudimentary psychological analysis, Part II. Bach, 17, 4-16.

Konečni, V. J. (1987). Response to Robert Batt. Music Perception, 5, 215-217.

Konečni, V. J. (1997). Vyacheslav Artyomov’s Requiem: A humanist's chef-d'oeuvre. Moscow: Fond duhovnogo tvorchestva.

Konečni, V. J. (2005). The aesthetic trinity: Awe, being moved, thrills. Bulletin of Psychology and the Arts, 5, 27-44.

Konečni, V. J., Brown, A., \& Wanic, R. A. (2008). Comparative effects of music and recalled lifeevents on emotional state. Psychology of Music, 36, 289-308.

Post, O. \& Huron, D. (2009). Western classical music in the minor mode is slower (except in the Romantic period). Empirical Musicology Review, Vol. 4, No. 1, 2-10.

\section{ENDNOTE}

${ }^{1}$ Analogous questions have been raised for the ordering, in terms of tempo (often combined with other variables that can be regarded as having psychological impact), of the components of Bach's St Matthew Passion (Konečni, 1986), and, more generally, in the ordering of the components of the Latin mass (including the Latin requiem). I have argued that analogously with some aspects of the design of mediaeval cathedrals, the Roman Catholic Church has intuitively arranged the components of missa ordinarium and missa pro defunctis - perhaps most clearly in terms of tempo - in a manner that has psychological implications and benefits (cf. Konečni, 1997, 2005). 